\title{
Effects of cyclophosphamide combined with prednisone on TNF- $\alpha$ expression in treatment of patients with interstitial lung disease
}

\author{
$\mathrm{JUN} \mathrm{LI}^{1}, \mathrm{XIULING} \mathrm{CHEN}{ }^{2}$ and YUNPING QU ${ }^{3}$ \\ ${ }^{1}$ Department of Respiratory Medicine, Jinan Central Hospital Affiliated to Shandong University; \\ Departments of ${ }^{2}$ Gynaecology and Obstetrics, and ${ }^{3}$ Stomatology, \\ First People's Hospital of Jinan, Jinan, Shandong 250014, P.R. China
}

Received September 19, 2018; Accepted August 06, 2019

DOI: $10.3892 /$ etm.2019.8099

\begin{abstract}
Effects of cyclophosphamide combined with prednisone on TNF- $\alpha$ expression in the treatment of patients with interstitial lung disease (ILD), and its clinical significance were investigated. A prospective analysis was performed on 198 patients with ILD in Jinan Central Hospital Affiliated to Shandong University from January 2010 to December 2017. Among them, 101 patients treated with cyclophosphamide combined with prednisone were assigned in the combined treatment group, and 97 patients treated with prednisone alone in the control group. Patients in the two groups were compared in terms of lung function, St. George's Respiratory Questionnaire (SGRQ) score, clinical efficacy, adverse reactions and TNF- $\alpha$ expression levels before and after treatment. After treatment, the patients in the combined treatment group had significantly higher forced vital capacity (FVC) and forced expiratory volume in first second (FEV1) compared with the control group, but significantly lower diffusing capacity of lung for carbon monoxide (DLCO) and DLCO\% $(\mathrm{P}<0.05)$. In both groups, patients after treatment had higher FVC and FEV1, but lower DLCO and DLCO\% $(\mathrm{P}<0.05)$, compared with before treatment, while SGRQ score before treatment was higher than that after treatment $(\mathrm{P}<0.05)$. Compared with control group, the combined treatment group had significantly more patients with complete remission (CR) and higher total effective rate, however less patients with stable disease $(\mathrm{SD})(\mathrm{P}<0.05)$. Patients with adverse reactions in the combined treatment group were less than those in the control group $(\mathrm{P}<0.05)$. After treatment, TNF- $\alpha$ expression level in the combined treatment group was significantly lower than that in the control group
\end{abstract}

Correspondence to: Dr Yunping Qu, Department of Stomatology, First People's Hospital of Jinan, 132 Daminghu Road, Lixia, Jinan, Shandong 250014, P.R. China

E-mail: aqu9nz@163.com; 2251523480@qq.com

Key words: cyclophosphamide, prednisone, combined treatment, interstitial lung disease, TNF- $\alpha$
$(\mathrm{P}<0.05)$, and TNF- $\alpha$ expression before treatment was higher than that after treatment in both groups $(\mathrm{P}<0.05)$. In conclusion, cyclophosphamide combined with prednisone is effective and safe in the treatment of ILD without severe adverse reactions, reducing TNF- $\alpha$ expression level, and therefore is worthy of clinical application.

\section{Introduction}

Interstitial lung disease (ILD), also known as diffuse parenchymal lung disease, is common in the respiratory system accounting for $14-16 \%$ of respiratory diseases $(1,2)$. The incidence rate of the disease has increased with industrialization (3), and the cause of this disease may be related to air pollution and viral infection, according to the study of Salisbury et al (4). With less obvious specific symptoms in the early stage, the disease is usually ignored by patients who therefore miss the best treatment time (5). Lesions of ILD with complex onset are mainly in the alveolar wall and the surrounding tissue of the alveoli, so patients may suffer from pulmonary fibrosis if not treated in time. Moreover, ILD even causes respiratory failure with disease progression, posing a serious threat to the patient's life $(6,7)$. Therefore, it is important to choose an effective treatment plan with few adverse reactions.

At present, ILD is symptomatically treated with antibiotics and glucocorticoids (8). Prednisone inhibits the aggregation of macrophages and leukocytes, and has anti-inflammatory response and anti-stress reaction (9). Cyclophosphamide blocks B-cell proliferation and inhibits the antibody production, as well as complements immunoadsorption due to its long action time, thereby ensuring good efficacy (10). According to a study by Reece et al (11), prednisone alone improves renal function in the treatment of multiple myeloma, however its total effective rate is lower than that of prednisone combined with cyclophosphamide. As a tumor necrosis factor, widely present in alveoli and histocytes, and an important factor in immune mediation, TNF- $\alpha$ produced by macrophages and neutrophils is abundantly expressed in the presence of pneumonia and kills abnormal cells, which induces the release of other inflammatory factors (12). 
Currently, there are few studies on cyclophosphamide combined with hormones for the treatment of ILD. Therefore, in the present study, a retrospective analysis was performed on the medical records of patients with ILD, and prednisone alone was compared with cyclophosphamide combined with prednisone in terms of efficacy, adverse reactions and TNF- $\alpha$ expression levels, before and after treatment, in order to provide a reference for the clinical treatment of ILD.

\section{Patients and methods}

Clinical information. A prospective analysis was performed on 198 patients with ILD in Jinan Central Hospital Affiliated to Shandong University (Jinan, China) from January 2010 to December 2017. In total, 131 males and 67 females, aged 21-70 years, were included, with an average age of $57.34 \pm 4.54$ years. Among them, 101 patients treated with cyclophosphamide combined with prednisone were assigned in the combined treatment group, and 97 patients treated with prednisone alone in the control group. Inclusion criteria: Patients with early and intermediate stages of ILD who were diagnosed by chest imaging, pulmonary ventilation and diffusion functions, pathological biopsy; patients in the two groups with balanced severity; patients of $\leq 70$ years of age; patients with complete medical records; patients who had not been diagnosed and treated in other hospitals. Exclusion criteria: Patients allergic to the drugs of the study; patients with other respiratory diseases; pregnant or lactating women; patients with acute gastrointestinal bleeding or other severe diseases; patients with communication or cognitive disorders. All patients and their families signed an informed consent form and cooperated with the medical staff to complete the relevant medical treatment. The study was approved by the Ethics Committee of Jinan Central Hospital Affiliated to Shandong University.

Methods. Patients in the control group were treated with prednisone, $10 \mathrm{mg} /$ time and 3 times/day (Zhejiang Xianju Pharmaceutical Co., Ltd.; SFDA approval no. H33021207) for 4 consecutive weeks. After that, the dosage was gradually reduced according to the patient's condition. In the combined treatment group, the patients were intravenously dripped with cyclophosphamide for infusion, $4 \mathrm{mg} / \mathrm{kg}$ and 1 time/day (Jiangsu Hengrui Pharmaceutical Co., Ltd.; SFDA approval no. H32020856) for 3 consecutive weeks. After that, the dosage was gradually reduced according to the patient's condition. Both groups of patients were treated for 12 weeks.

Spirometer (Jaeger, Ltd.) was used to detect the forced vital capacity (FVC), the forced expiratory volume in first second (FEV1), the diffusing capacity of lung for carbon monoxide (DLCO) and DLCO\% before and at 12 weeks after treatment. Fasting venous blood was extracted and centrifuged at $3,000 \mathrm{x}$ for $15 \mathrm{~min}$ at $4^{\circ} \mathrm{C}$ on admission and at 12 weeks after treatment, in order to determine TNF- $\alpha$ with enzyme-linked immunosorbent assay (ELISA), following strictly the manufacturer's instructions of TNF- $\alpha$ kit (Shanghai Yuanmu Biological Technology Co., Ltd.; cat. no. YM-QP10200). The St. George's Respiratory Questionnaire (SGRQ) score was used to evaluate patients' quality of life with a total score of 100 points. The higher the score, the better the activity was. Changes in indicator levels and the incidence rate of adverse reactions were recorded and compared between the two groups.

Criteria for efficacy evaluation. The clinical efficacy on ILD was evaluated based on chest CT before and after treatment, referring to relevant criteria (13). Complete remission (CR): Target lesions partially disappeared, and the pleural edge was regular. Partial remission (PR): Lesions had ground-glass opacities, with reduced stripes and reticular shadows. Stable disease (SD): No significant changes in target lesions. Progressive disease (PD): Lesions had ground-glass opacities, with increased stripes and reticular shadows, or lesions had honeycomb opacities. The clinical total effective rate $=(\mathrm{CR}+\mathrm{PR}) /($ total number of cases $) \times 100 \%$.

Statistical analysis. SPSS 17.4 software (Beijing NDTimes Technology Co., Ltd.) was used for statistical analysis. Enumeration data were expressed as n (\%) and tested by Chi-square test. Measurement data were expressed as the mean \pm standard deviation, and t-test was used for the differences between two groups. Paired t-test was used for comparison of the data before and after treatment. Data among multiple groups were compared with ANOVA and Dunnett's post hoc test. $\mathrm{P}<0.05$ was considered to indicate a statistically significant difference.

\section{Results}

Comparison of clinical information. There were no significant differences between the two groups in terms of sex, age, dyspnea, mucopurulent sputum, anorexia, weakness, arthralgia in limbs, fever or alveolitis $(\mathrm{P}>0.05)$. Thus, the groups were comparable (Table I).

Comparison of lung function indices before and after treatment. Before treatment, there were no statistically significant differences between the two groups in FVC, FEV1, DLCO or DLCO\% $(\mathrm{P}>0.05)$. After treatment, the patients in the combined treatment group had significantly higher FVC and FEV1 compared with the control group, however significantly lower DLCO and DLCO\% $(\mathrm{P}<0.05)$. In the combined treatment and control groups, the patients after treatment had higher FVC and FEV1, but lower DLCO and DLCO\%, compared with before treatment $(\mathrm{P}<0.05)$ (Table II and Fig. 1).

Comparison of SGRQ score before and after treatment. Before treatment, there was no statistically significant difference between the two groups in SGRQ score $(\mathrm{P}>0.05)$. However, after treatment the SGRQ score in the combined treatment group was significantly higher than that in the control group $(\mathrm{P}<0.05)$. In the combined treatment and control groups, SGRQ scores before treatment were higher than those after treatment $(\mathrm{P}<0.05)$ (Table III).

Comparison of efficacy before and after treatment. There were no statistically significant differences in patients with PR or PD between the combined treatment and control groups 
Table I. Basic patient information of the combined-treatment group and the control group [n (\%)].

\begin{tabular}{|c|c|c|c|c|}
\hline Characteristics & $\begin{array}{l}\text { Combined treatment } \\
\text { group }(n=101)\end{array}$ & $\begin{array}{l}\text { Control group } \\
\qquad(\mathrm{n}=97)\end{array}$ & $\chi^{2}$ & P-value \\
\hline Sex & & & 0.125 & 0.724 \\
\hline Male & $68(67.33)$ & $63(64.95)$ & & \\
\hline Female & $33(32.67)$ & $34(35.05)$ & & \\
\hline Age (years) & & & 0.061 & 0.805 \\
\hline$<45$ & $35(34.65)$ & $32(32.99)$ & & \\
\hline$\geq 45$ & $66(65.35)$ & $65(67.01)$ & & \\
\hline Dyspnea & & & 0.432 & 0.511 \\
\hline Yes & $78(77.23)$ & $71(73.20)$ & & \\
\hline No & $23(22.77)$ & $26(26.80)$ & & \\
\hline Mucous purulent sputum & & & 0.116 & 0.733 \\
\hline Yes & $72(71.29)$ & $67(69.07)$ & & \\
\hline No & $29(28.71)$ & $30(30.93)$ & & \\
\hline Anorexia & & & 1.011 & 0.315 \\
\hline Yes & $64(63.37)$ & $68(70.10)$ & & \\
\hline No & $37(36.63)$ & $29(29.90)$ & & \\
\hline Weakness & & & 0.322 & 0.980 \\
\hline Yes & $73(72.28)$ & $76(78.35)$ & & \\
\hline No & $28(27.72)$ & $21(21.65)$ & & \\
\hline Arthralgia in limbs & & & 1.175 & 0.278 \\
\hline Yes & $69(68.32)$ & $73(75.26)$ & & \\
\hline No & $32(31.68)$ & $24(24.74)$ & & \\
\hline Fever & & & 0.615 & 0.433 \\
\hline Yes & $58(57.43)$ & $61(62.89)$ & & \\
\hline No & $43(42.57)$ & $36(37.11)$ & & \\
\hline Cell type in alveolar structure & & & 0.807 & 0.369 \\
\hline Neutrophil-type pulmonary fibrosis & $54(53.47)$ & $58(59.79)$ & & \\
\hline Lymphocyte-type pulmonary fibrosis & $47(46.53)$ & $39(40.21)$ & & \\
\hline
\end{tabular}

Table II. Comparison of lung function before and after treatment between the combined treatment group and the control group.

\begin{tabular}{|c|c|c|c|c|}
\hline Group & FVC (1) & FEV1 (1) & DLCO (1) & $\operatorname{DLCO}(\%)$ \\
\hline \multicolumn{5}{|c|}{ Combined treatment group $(n=101)$} \\
\hline Before treatment & $2.48 \pm 0.57$ & $2.06 \pm 0.71$ & $5.64 \pm 2.84$ & $66.51 \pm 13.12$ \\
\hline After treatment & $2.83 \pm 1.25$ & $2.64 \pm 1.06$ & $3.57 \pm 1.15$ & $46.67 \pm 7.34$ \\
\hline $\mathrm{t}$ & 2.560 & 4.569 & 6.790 & 13.260 \\
\hline P-value & 0.011 & $<0.001$ & $<0.001$ & $<0.001$ \\
\hline \multicolumn{5}{|c|}{ Control group $(\mathrm{n}=97)$} \\
\hline Before treatment & $2.49 \pm 0.46^{\mathrm{a}}$ & $2.04 \pm 0.54^{\mathrm{a}}$ & $5.61 \pm 2.79^{a}$ & $65.82 \pm 12.89^{\mathrm{a}}$ \\
\hline After treatment & $2.62 \pm 0.42^{b}$ & $2.31 \pm 0.92^{\mathrm{b}}$ & $4.22 \pm 1.53^{\mathrm{b}}$ & $56.25 \pm 11.63^{\mathrm{b}}$ \\
\hline $\mathrm{t}$ & 2.055 & 2.493 & 4.302 & 4.294 \\
\hline P-value & 0.041 & 0.014 & $<0.001$ & $<0.001$ \\
\hline
\end{tabular}

${ }^{\mathrm{a}} \mathrm{P}>0.05$, not significant compared with the combined treatment group before treatment. ${ }^{\mathrm{b}} \mathrm{P}<0.05$, statistically significant compared with the combined treatment group after treatment. FVC, forced vital capacity; FEV1, forced expiratory volume in first second; DLCO, diffusing capacity of lung for carbon monoxide.

(both $\mathrm{P}>0.05$ ). Compared with the control group, the combined treatment group had significantly more patients with $\mathrm{CR}$ and significantly higher total effective rate, but less patients with SD $(\mathrm{P}<0.05)$ (Table IV). 

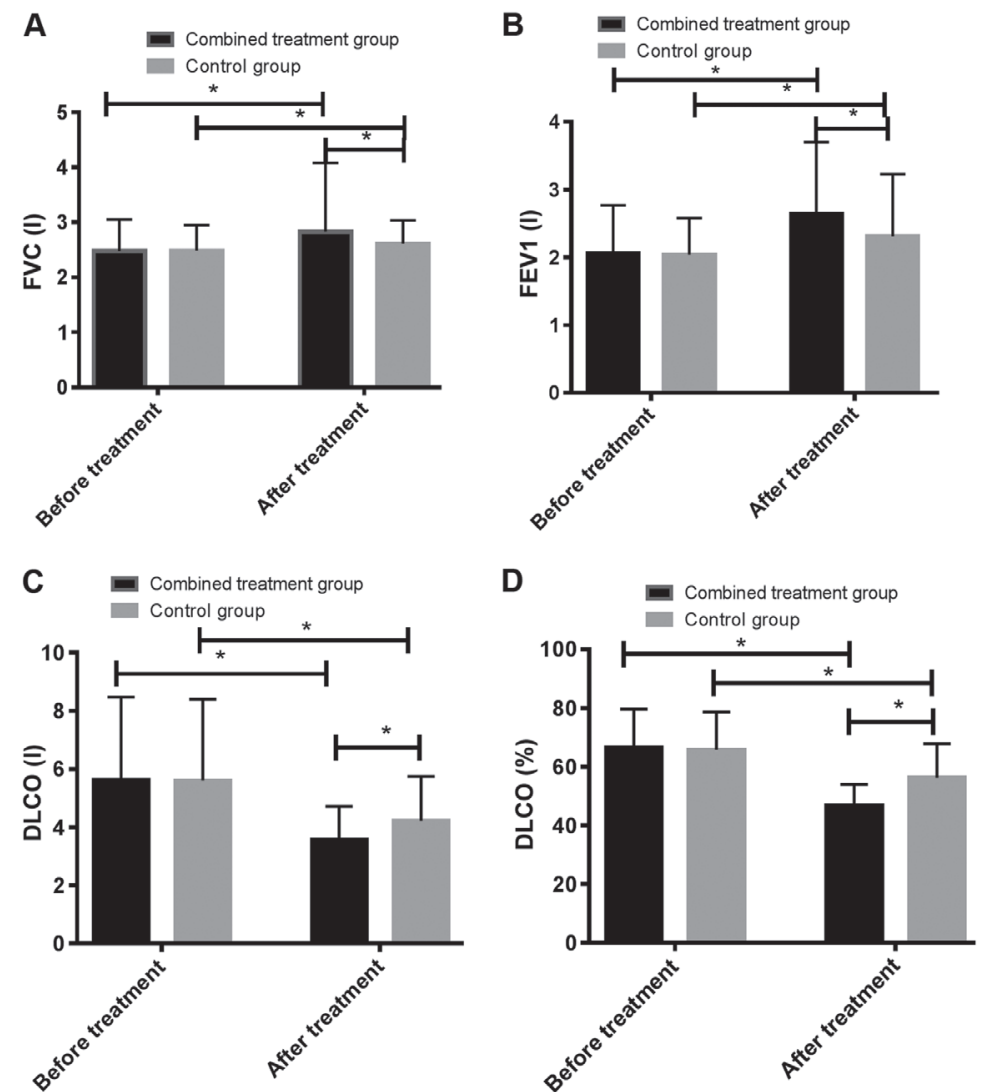

Figure 1. Comparison of lung function indicators before and after treatment in the combined treatment group and the control group. (A) After treatment, the FVC index of the combined treatment group was significantly higher than that of the control group, and the FVC index after treatment in the two groups was higher than that before treatment. (B) After treatment, the FEV1 index of the combined treatment group was significantly higher than that of the control group. In the two groups, the FEV1 index after treatment was higher than that before treatment. (C) After treatment, the DLCO index of the combined treatment group was significantly lower than that of the control group, and the DLCO index after treatment in the two groups was lower than that before treatment. (D) The DLCO\% index of the combined treatment group was significantly lower than that of the control group, and the DLCO\% index after treatment in the two groups was lower than before treatment. "P<0.05. FVC, forced vital capacity; FEV1, forced expiratory volume in first second; DLCO, diffusing capacity of lung for carbon monoxide

Table III. Comparison of SGRQ score before and after treatment between the combined treatment group and the control group.

\begin{tabular}{lcccr}
\hline Group & Combined treatment group $(\mathrm{n}=101)$ & Control group $(\mathrm{n}=97)$ & $\mathrm{t}$ & P-value \\
\hline Before treatment & $62.38 \pm 13.27$ & $61.75 \pm 12.86$ & 0.339 & 0.735 \\
After treatment & $46.84 \pm 11.81$ & $35.51 \pm 9.57$ & 7.399 & $<0.001$ \\
$\mathrm{t}$ & 8.792 & 16.12 & & \\
P-value & $<0.001$ & $<0.001$ & & \\
\hline
\end{tabular}

SGRQ, St. George's Respiratory Questionnaire.

Table IV. Comparison of treatment efficacy before and after treatment between the combined treatment group and the control group $[\mathrm{n}(\%)]$.

\begin{tabular}{lcccc}
\hline Treatment outcome & Combined treatment group $(\mathrm{n}=101)$ & Control group $(\mathrm{n}=97)$ & $\chi^{2}$ & P-value \\
\hline $\mathrm{CR}$ & $51(50.50)$ & $35(36.08)$ & 4.183 & 0.041 \\
$\mathrm{PR}$ & $35(34.65)$ & $33(34.02)$ & 0.009 & 0.925 \\
$\mathrm{SD}$ & $14(13.86)$ & $25(25.77)$ & 4.439 & 0.035 \\
PD & $1(1.0)$ & $4(4.12)$ & 1.974 & 0.160 \\
Total effective rate & $86(85.15)$ & $68(70.10)$ & 6.480 & 0.011 \\
\hline
\end{tabular}

CR, complete remission; $\mathrm{PR}$, partial remission; $\mathrm{SD}$, stable disease; $\mathrm{PD}$, progressive disease. 
Table V. Comparison of adverse reactions before and after treatment between the combined treatment group and the control group $[\mathrm{n}(\%)]$.

\begin{tabular}{|c|c|c|c|c|}
\hline Adverse reaction & Combined treatment group $(n=101)$ & Control group $(n=97)$ & $\chi^{2}$ & P-value \\
\hline Gastrointestinal reaction & $6(5.94)$ & $14(14.43)$ & 3.930 & 0.047 \\
\hline Elevated blood glucose & $2(1.98)$ & $8(8.25)$ & 4.053 & 0.044 \\
\hline Chemical cystitis & $1(1.0)$ & $6(6.19)$ & 3.916 & 0.048 \\
\hline Others & $4(3.96)$ & $12(12.37)$ & 4.712 & 0.030 \\
\hline
\end{tabular}

Table VI. Changes in blood TNF- $\alpha$ levels in patients before and after treatment in the combined treatment group and the control group (ng/l).

\begin{tabular}{lccr}
\hline Group & Combined treatment group $(\mathrm{n}=101)$ & Control group $(\mathrm{n}=97)$ & $\mathrm{t}$ \\
\hline Before treatment & $21.83 \pm 4.22$ & $22.14 \pm 4.53$ & 0.498 \\
After treatment & $11.56 \pm 3.26$ & $16.13 \pm 4.15$ & 8.635 \\
$\mathrm{t}$ & 4.079 & 4.264 & $<0.001$ \\
P-value & $<0.001$ & $<0.001$ & \\
\hline
\end{tabular}
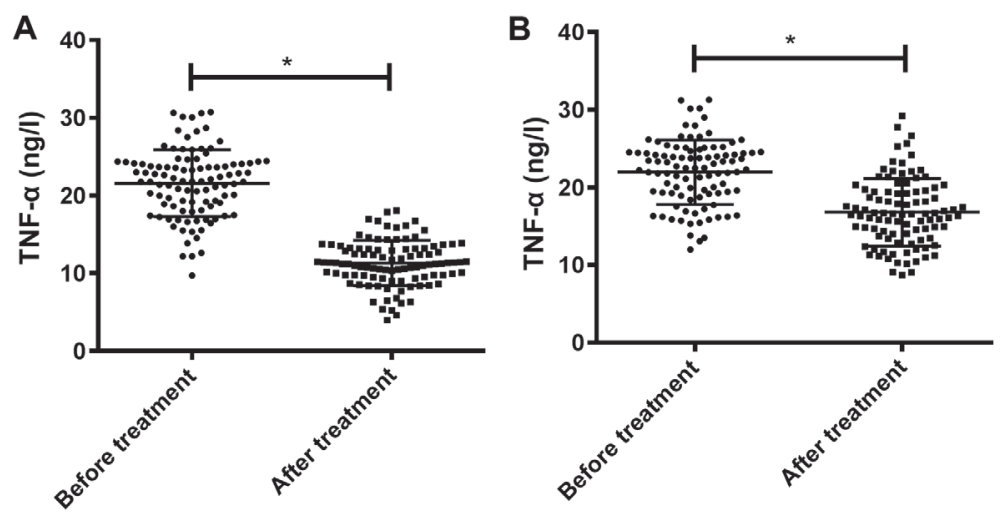

Figure 2. Comparison of TNF- $\alpha$ expression level before and after treatment. TNF- $\alpha$ expression level was determined by ELISA. (A) The expression of TNF- $\alpha$ levels before treatment in the combined treatment group was higher than that after treatment. (B) The expression of TNF- $\alpha$ levels in the control group before treatment was higher than that after treatment. ${ }^{*} \mathrm{P}<0.05$.

Comparison of adverse reactions before and after treatment. The combined treatment group had less patients with gastrointestinal reactions, hyperglycemia and chemical cystitis than the control group $(\mathrm{P}<0.05)$ (Table $\mathrm{V})$.

Comparison of TNF- $\alpha$ expression level before and after treatment. In the combined treatment group, TNF- $\alpha$ expression levels before and after treatment were $21.83 \pm 4.22$ and $11.56 \pm 3.26 \mathrm{ng} / 1$, respectively, and in the control group were $22.14 \pm 4.53$ and $16.13 \pm 4.15 \mathrm{ng} / \mathrm{l}$, respectively. Before treatment, there was no statistically significant difference between the two groups in TNF- $\alpha$ expression level $(\mathrm{P}>0.05)$. However, the TNF- $\alpha$ expression in the combined treatment group after treatment was significantly lower than that in the control group $(\mathrm{P}<0.05)$. In the combined treatment and control groups, TNF- $\alpha$ expression levels before treatment were higher than those after treatment $(\mathrm{P}<0.05)$ (Table VI and Fig. 2).

\section{Discussion}

Heterogeneous ILD has complex causes, so its pathogenesis remains unclear (14). The disease has no special symptoms in the early stage, so it is diagnosed through etiology, pathological manifestations and imaging features. As a result, most patients are in the advanced stage of irreversible pulmonary fibrosis when diagnosed. In the advanced stage of ILD, inflammation spreads to blood vessels and the interstitium, destroys the lung tissue and leads to pulmonary fibrosis, which damages the lung function, increases the difficulty of treatment and causes patient death (15). With the advancement of modern medicine, ILD is controlled but difficult to cure, with high incidence and mortality rates and a long treatment cycle (16). Therefore, timely drug treatment is the key to control the deterioration of the disease. ILD is currently treated based on anti-pulmonary fibrosis and anti-inflammation. 
In the present study, a prospective analysis was performed on 198 patients with ILD in Jinan Central Hospital Affiliated to Shandong University from January 2010 to December 2017. Patients in the combined treatment and control groups were compared in terms of efficacy, adverse reactions and TNF- $\alpha$ expression level, before and after treatment. The results of lung function tests, efficacy and SGRQ score before and after treatment in the combined treatment group were better than those in the control group. Anti-inflammatory and anti-allergic prednisone regulates protein biosynthesis and metabolism, reduces connective tissue proliferation and inflammatory exudation, and inhibits histamine formation and release (17). The inflammatory state of advanced ILD is less obvious, however, the lung becomes gradually fibrotic with disease progression, so anti-fibrotic therapy is necessary for the patients (18). According to a study (19), the efficacy of hormones is not significant on systemic sclerosis-associated ILD, so the disease is currently treated with prednisone combined with cyclophosphamide. Cyclophosphamide treats autoimmune diseases, and restricts the transformation of viruses into immunoblasts through non-specifically killing small lymphocytes $(20,21)$. According to a study by Mok (22), cyclophosphamide combined with prednisone in the treatment of lupus nephritis was shown to have a high total effective rate, suggesting that the combination treatment improves the patient results of lung function tests and quality of life, which further supports the results of this study. In the present study, patients with gastrointestinal reactions, hyperglycemia and chemical cystitis in the combined treatment group were less than those in the control group. Prednisone leads to hyperglycemia through promoting protein to convert into sugar, and gastrointestinal reactions and other adverse reactions through promoting gastric secretion (23). Cyclophosphamide interferes with the production of DNA and RNA, and cross-links with the former, thereby inhibiting the immune response, proliferation and division of immune lymphocytes, and blocking immune complex deposition, so as to treat diseases. Due to fewer adverse reactions, cyclophosphamide has been widely used in the treatment of lymphatic systemic and autoimmune diseases (24). According to a study by Mulvenna et al (25), non-small cell lung cancer weakens lung function, and the high incidence rate of adverse reactions after treatment with prednisone reduces the immune function of the body, and therefore adverse reactions occur easily. In comparison of TNF- $\alpha$ expression levels before treatment, there was no statistically significant difference between the two groups, whereas after treatment, TNF- $\alpha$ expression level was significantly lower in the combined treatment group than that in the control group. TNF- $\alpha$ mediates the expression of inflammatory factors, aggravates inflammatory responses and proliferates fibroblasts. A large amount of collagen secretion causes the occurrence and development of pulmonary fibrosis, which plays a key role in respiratory diseases. Therefore, the combined treatment reduces TNF- $\alpha$ expression level (26).

In this investigation, due to the small number of patients with ILD in Jinan Central Hospital Affiliated to Shandong University, the sample size is small, so there may be contingency in the results. Therefore, a longer-term follow-up survey will be conducted in the future.

In conclusion, cyclophosphamide combined with prednisone is effective and safe in the treatment of ILD, without severe adverse reactions and reducing the TNF- $\alpha$ expression level, and therefore is worthy of clinical promotion.

\section{Acknowledgements}

Not applicable.

\section{Funding}

No funding was received.

\section{Availability of data and materials}

The datasets used and/or analyzed during the present study are available from the corresponding author on reasonable request.

\section{Authors' contributions}

JL performed ELISA and wrote the manuscript. XC and YQ collected and interpreted the general data of the patients and were responsible for the statistical analysis. All authors read and approved the final manuscript.

\section{Ethics approval and consent to participate}

The study was approved by the Ethics Committee of Jinan Central Hospital Affiliated to Shandong University (Jinan, China). Patients who participated in this research, signed an informed consent and had complete clinical data.

\section{Patient consent for publication}

Not applicable.

\section{Competing interests}

The authors declare that they have no competing interests.

\section{References}

1. Hagmeyer L, Theegarten D, Wohlschläger J, Treml M, Matthes S, Priegnitz C and Randerath WJ: The role of transbronchial cryobiopsy and surgical lung biopsy in the diagnostic algorithm of interstitial lung disease. Clin Respir J 10: 589-595, 2016.

2. Anthimopoulos M, Christodoulidis S, Ebner L, Christe A and Mougiakakou S: Lung pattern classification for interstitial lung diseases using a deep convolutional neural network. IEEE Trans Med Imaging 35: 1207-1216, 2016.

3. Douglas WW, Tazelaar HD, Hartman TE, Hartman RP, Decker PA, Schroeder DR and Ryu JH: Polymyositis-dermatomyositis-associated interstitial lung disease. Am J Respir Crit Care Med 164: 1182-1185, 2001

4. Salisbury ML, Xia M, Murray S, Bartholmai BJ, Kazerooni EA, Meldrum CA, Martinez FJ and Flaherty KR: Predictors of idiopathic pulmonary fibrosis in absence of radiologic honeycombing: A cross sectional analysis in ILD patients undergoing lung tissue sampling. Respir Med 118: 88-95, 2016.

5. Johannson KA, Marcoux VS, Ronksley PE and Ryerson CJ: Diagnostic yield and complications of transbronchial lung cryobiopsy for interstitial lung disease. A systematic review and metaanalysis. Ann Am Thorac Soc 13: 1828-1838, 2016.

6. Solomon JJ, Chung JH, Cosgrove GP, Demoruelle MK, Fernandez-Perez ER, Fischer A, Frankel SK, Hobbs SB, Huie TJ, Ketzer J, et al: Predictors of mortality in rheumatoid arthritis-associated interstitial lung disease. Eur Respir J 47: 588-596, 2016.

7. Mathai SC and Danoff SK: Management of interstitial lung disease associated with connective tissue disease. BMJ 352: h6819, 2016. 
8. Wallace B, Vummidi D and Khanna D: Management of connective tissue diseases associated interstitial lung disease: A review of the published literature. Curr Opin Rheumatol 28: 236-245, 2016.

9. Park SI,Felipe CR, Pinheiro-Machado PG, Garcia R, Fernandes FB, Casarini DE, Tedesco-Silva H Jr and Medina-Pestana JO: Tacrolimus pharmacokinetic drug interactions: Effect of prednisone, mycophenolic acid or sirolimus. Fundam Clin Pharmacol 23 137-145, 2009.

10. Eichhorst B, Fink AM, Bahlo J, Busch R, Kovacs G, Maurer C, Lange E, Köppler H, Kiehl M, Sökler M, et al; international group of investigators; German CLL Study Group (GCLLSG): First-line chemoimmunotherapy with bendamustine and rituximab versus fludarabine, cyclophosphamide, and rituximab in patients with advanced chronic lymphocytic leukaemia (CLL10): An international, open-label, randomised, phase 3 , non-inferiority trial. Lancet Oncol 17: 928-942, 2016.

11. Reece DE, Trieu Y, Masih-Khan E, Atenafu EG, Chen C, Prica A Tiedemann R, Trudel S and Kukreti V: Cyclophosphamide and bortezomib with prednisone or dexamethasone for the treatment of relapsed and refractory multiple myeloma. Clin Lymphoma Myeloma Leuk 16: 387-394, 2016.

12. He QQ, He X, Wang YP, Zou Y, Xia QJ, Xiong LL, Luo CZ, $\mathrm{Hu}$ XS, Liu J and Wang TH: Transplantation of bone marrowderived mesenchymal stem cells (BMSCs) improves brain ischemia-induced pulmonary injury in rats associated to TNF- $\alpha$ expression. Behav Brain Funct 12: 9, 2016.

13. Ryerson CJ, Cayou C, Topp F, Hilling L, Camp PG, Wilcox PG, Khalil N, Collard HR and Garvey C: Pulmonary rehabilitation improves long-term outcomes in interstitial lung disease: A prospective cohort study. Respir Med 108: 203-210, 2014.

14. Trudzinski FC, Kaestner F, Schäfers HJ, Fähndrich S, Seiler F, Böhmer P, Linn O, Kaiser R, Haake H, Langer F, et al: Outcome of patients with interstitial lung disease treated with extracorporeal membrane oxygenation for acute respiratory failure. Am J Respir Crit Care Med 193: 527-533, 2016.

15. Volkmann ER and Tashkin DP: Treatment of systemic sclerosis-related interstitial lung disease: A review of existing and emerging therapies. Ann Am Thorac Soc 13: 2045-2056, 2016.

16. Hutchinson JP, Fogarty AW, McKeever TM and Hubbard RB: In-hospital mortality after surgical lung biopsy for interstitial lung disease in the United States. 2000 to 2011. Am J Respir Crit Care Med 193: 1161-1167, 2016.

17. Chen H, Zhong JM, Yi ZS, Zha J, Chen Y and Cai LY: Immunological mechanism of prednisone in the treatment of infantile spasm. Zhongguo Dang Dai Er Ke Za Zhi 19: 1044-1050, 2017 (In Chinese).
18. Witt LJ, Demchuk C, Curran JJ and Strek ME: Benefit of adjunctive tacrolimus in connective tissue disease-interstitial lung disease. Pulm Pharmacol Ther 36: 46-52, 2016.

19. Kundu S, Paul S, Hariprasath K, Agarwal R, Ghosh S and Biswas D Effect of sequential intravenous pulse cyclophosphamide-azathioprine in systemic sclerosis-interstitial lung disease: An open-label study. Indian J Chest Dis Allied Sci 58: 7-10, 2016.

20. Yunyun F, Yu C, Panpan Z, Hua C, Di W, Lidan Z, Linyi P, Li W, Qingjun W, Xuan Z, et al: Efficacy of cyclophosphamide treatment for immunoglobulin G4-related disease with addition of glucocorticoids. Sci Rep 7: 6195, 2017.

21. Daillère R, Vétizou M, Waldschmitt N, Yamazaki T, Isnard C, Poirier-Colame V, Duong CPM, Flament C, Lepage P, Roberti MP, et al: Enterococcus hirae and Barnesiella intes tinihominis facilitate cyclophosphamide-induced therapeutic immunomodulatory effects. Immunity 45: 931-943, 2016.

22. Mok CC: Con: Cyclophosphamide for the treatment of lupus nephritis. Nephrol Dial Transplant 31: 1053-1057, 2016.

23. Gerards MC, Venema GE, Patberg KW, Kross M, Potter van Loon BJ, Hageman IMG, Snijders D, Brandjes DPM, Hoekstra JBL Vriesendorp TM, et al: Dapagliflozin for prednisone-induced hyperglycaemia in acute exacerbation of chronic obstructive pulmonary disease. Diabetes Obes Metab 20: 1306-1310, 2018

24. Tashkin DP, Roth MD, Clements PJ, Furst DE, Khanna D, Kleerup EC, Goldin J, Arriola E, Volkmann ER, Kafaja S, et al; Sclerodema Lung Study II Investigators: Mycophenolate mofetil versus oral cyclophosphamide in scleroderma-related interstitial lung disease (SLS II): A randomised controlled, double-blind, parallel group trial. Lancet Respir Med 4: 708-719, 2016.

25. Mulvenna P, Nankivell M, Barton R, Faivre-Finn C, Wilson P, McColl E, Moore B, Brisbane I, Ardron D, Holt T, et al: Dexamethasone and supportive care with or without whole brain radiotherapy in treating patients with non-small cell lung cancer with brain metastases unsuitable for resection or stereotactic radiotherapy (QUARTZ): Results from a phase 3, non-inferiority, randomised trial. Lancet 388: 2004-2014, 2016.

26. Huang AX, Lu LW, Liu WJ and Huang M: Plasma inflammatory cytokine IL-4, IL-8, IL-10, and TNF- $\alpha$ levels correlate with pulmonary function in patients with asthma - chronic obstructive pulmonary disease (COPD) overlap syndrome. Med Sci Monit 22: 2800-2808, 2016.

This work is licensed under a Creative Commons Attribution-NonCommercial-NoDerivatives 4.0 International (CC BY-NC-ND 4.0) License. 